Canadian Journal of Fisheries and Aquatic Sciences, Vol. 56, No. 4, 1999, pp. 527-538.

ISSN: 0706-652X

doi:10.1139/cjfas-56-4-527

http://pubs.nrc-cnrc.gc.ca/eng/index.html

http://article.pubs.nrc-

cnrc.gc.ca/RPAS/RPViewDoc? handler $=$ HandleInitialGet\&calyLang=eng\&journal=cjfas\&volume=56\&articleFile

$=$ f98-193.pdf

(C) 1999 All rights reserved. Research Press, National Research Council of Canada.

\title{
Modeling sources of variation for growth and predatory demand of Lake Erie walleye (Stizostedion vitreum), 1986-1995
}

\author{
Mark W. Kershner, Denise M. Schael, Roger L. Knight, Roy A. Stein,, and Elizabeth A. \\ Marschall
}

M.W. Kershner, D.M. Schael, R.A. Stein, and E.A. Marschall. Aquatic Ecology Laboratory, Department of Evolution, Ecology, and Organismal Biology, Ohio State University.

R.L. Knight. Ohio Department of Natural Resources, Division of Wildlife, Sandusky Fish Research Unit.

\begin{abstract}
Given the variable nature of the Lake Erie ecosystem, we investigated biotic and abiotic sources of variation for walleye (Stizostedion vitreum) growth, consumption, and population-wide predatory demand. We determined how temperature, population structure, and age-specific consumption influenced walleye growth and consumption during 1986-1995. For each year, we used individual-based bioenergetics modeling to compare growth and consumption by walleye in Lake Erie's western or central basin with those of walleye moving seasonally between basins. Population structure strongly affected walleye growth and consumption but had little influence on interbasin growth rate comparisons. Based on water temperature alone, growth and consumption by western basin walleye were generally lower than for central basin or migratory populations and were more limited by summer water temperatures. In simulations combining effects of population structure, temperature, and age-specific consumption, migratory walleye grew most rapidly, taking advantage of temperature-related growth peaks in both basins. Estimates of walleye predatory demand declined with population size from 1988 through 1995 . With natural feedbacks, predatory demand interacts with prey production, limiting walleye reproductive potential when prey availability is low. However, immediate impact on predatory inertia is limited, complicating our ability to predict how predatory demand and prey availability interact in Lake Erie.
\end{abstract}

Résumé : Étant donné la nature variable de l'écosystème du lac Érié, nous avons examiné les sources biotiques et abiotiques de variation de la croissance, de la consommation et de la demande de prédation à l'échelle de la population chez le doré jaune (Stizostedion vitreum). Nous avons déterminé en quoi la température, la structure de la population et la consommation spécifique à l'âge influaient sur la croissance et la consommation des dorés entre 1986 et 1995. Pour chaque année, nous avons eu recours à la modélisation bioénergétique individuelle pour comparer la croissance et la consommation chez les dorés du bassin du centre ou de l'ouest du lac Érié et chez des dores qui se déplacent de façon saisonnière entre les bassins. La structure des populations affectait fortement la croissance et la consommation des dores jaunes, mais avait peu d'influence sur les comparaisons des taux de croissance entre bassins. Si l'on se fondait seulement sur la température, la croissance et la consommation chez les dorés jaunes du bassin occidental étaient dans 1 'ensemble inférieures à celles des dorés du bassin central ou des populations migratrices, et étaient plus limitées par les hautes températures estivales. Dans des simulations combinant les effets de la structure démographique, de la température et de la consommation spécifique à l'âge, les dorés migrateurs se développaient plus vite car ils tiraient profit des pics de croissance liés à la température dans les deux bassins. Les estimations de la demande de prédation des dorés ont baissé avec l'effectif de la population entre 1988 et 1995. Avec les rétroactions naturelles, la demande de prédation interagit avec la production de proies, limitant le potentiel génésique des dorés quand la disponibilité des proies est faible. Toutefois, l'impact immédiat sur l'inertie du comportement de prédation est limité, ce qui complique notre capacité de prédire le mode d'interaction entre la demande de prédation et la disponibilité des proies dans le lac Érié.

[Traduit par la Redaction] 


\section{Introduction}

Understanding the dynamic nature of carrying capacity is critically important to fisheries managers and aquatic ecologists, whose goals include assessment and understanding of factors affecting recruitment and survival of individual fish species. In many systems (e.g., the Great Lakes: Stewart et al. 1981; Stewart and Ibarra 1991; Jones et al. 1993), efforts focus on the balance between prey availability and predatory demand, as this relationship can determine the biomass and abundance of large piscivores (Carpenter et al. 1985). For example, in Lake Erie, concern has been raised regarding the capacity of the extant prey fish assemblage to support Lake Erie's walleye (Stizostedion vitreum) population, particularly during periods of shifting lake productivity.

In fact, biotic and abiotic characteristics of the Lake Erie ecosystem have changed substantially during the past 25-30 years (e.g., Makarewicz and Bertram 1991). With declines in lakewide phosphorus loading and a commensurate increase in water clarity, Lake Erie's trophic status has been rapidly shifting from eutrophy to mesotrophy in its western basin and from mesotrophy to oligotrophy in its central and eastern basins. During this time, western and central basin prey fish assemblages have experienced shifts in relative abundance among three prey types: ( $i$ ) spiny-rayed fishes (yellow perch (Perca flavescens), white perch (Morone americana), white bass (Morone chrysops), freshwater drum (Aplodinotus grunniens)), (ii) soft-rayed fishes (emerald shiner (Notropis atherinoides), spottail shiner (Notropis hudsonius), rainbow smelt (Osmerus mordax), trout-perch (Percopsis omiscomaycus)), and (iii) clupeids (gizzard shad (Dorosoma cepedianum), alewife (Alosa pseudoharengus)) (Knight and Vondracek 1993). These fluctuations within the prey assemblage are likely influenced by shifts in abiotic factors (e.g., lake trophic status, nutrient availability, and winter severity) and walleye predatory demand (Knight et al. 1984; Francis 1992; Hartman and Margraf 1992; Knight and Vondracek 1993). Walleye predatory demand, in turn, has been influenced by dramatic increases and fluctuations in walleye population size from 1970 to the present (Hatch et al. 1987; Knight 1997). Lake Erie also has endured numerous successful species invasions (e.g., zebra mussels (Dreissenia polymorpha), quagga mussels (Dreissena bugensis), white perch, round goby (Neogobius melanostomus), and a zooplankter, Bythotrephes cederstroemi) (Mills et al. 1993). More generally, variability of complex biotic and abiotic interactions in Lake Erie will determine the lake's carrying capacity for its top predator and associated prey assemblage. With this level of biotic and abiotic flux, the Lake Erie ecosystem represents a substantive challenge for fisheries managers and ecologists, who must balance short-term resource management goals (regarding walleye and their prey) with long-term resource sustainability, seeking what can only be described as a fix on a "moving target."

Given this variable ecosystem, we sought to gain insight into the influence of biotic and abiotic factors on variability associated with predatory demand in Lake Erie by modeling patterns of consumption and growth for walleye, the top predator. Lake Erie walleye differ from top predators in other Great Lakes in that they are naturally reproducing rather than stocked. Thus, natural feedback mechanisms may be in place to mediate walleye population dynamics. For example, Hartman and Margraf (1992) suggested that Lake Erie walleye growth was influenced by effects of walleye abundance on the prey fish assemblage. Growth and energetic condition of Lake Erie's walleye spawning stock and subsequent year-class strength appear to be strongly related (Henderson and Nepszy 1994), with fall gizzard shad (lipid-rich prey fish preferred by walleye) abundance strongly affecting walleye spawning success in the following spring (Madenjian et al. 1996). These results indicate the existence of a strong natural feedback 
mechanism between walleye growth and reproductive success.

Herein, we examine the relative importance of temperature regime and walleye age and size structure to patterns of walleye growth and consumption during 1986-1995. We incorporated walleye abundance and population structure, historically variable in Lake Erie, to account for "predatory inertia," a situation where increased predator abundance and (or) growth lead to increased predator biomass and predatory demand (Stewart et al. 1981; Carpenter et al. 1985). In addition, given evidence for seasonal walleye migration among Lake Erie's three basins (which differ in temperature regime and prey availability) and Lakes St. Clair and Huron (M. Turner (Ohio Department of Natural Resources, Division of Wildlife (ODNR-ODW), R. Haas (Michigan Department of Natural Resources), and S. Nepszy (Ontario Ministry of Natural Resources), unpublished tagging data), we explored the energetic consequences of seasonal migration by walleye.

To accomplish these goals, we used an individual-based bioenergetics model (Kitchell et al. 1977; Hewett and Johnson 1992) parameterized for walleye resident in Lake Erie's western and central basins during 1986-1995. For a given growing season, we modeled independent and combined effects of basin-specific temperature regimes, walleye age and size structure, and daily consumption rates to determine their effects on growth and consumption by walleye resident in either the western or central basin or walleye moving seasonally between them. Finally, to provide insight into the balance between predatory demand and prey production in Lake Erie, we generated annual estimates of population-wide walleye prey consumption during 1986-1995, quantifying year-to-year variability in the importance of temperature regime and walleye population structure and population size to predatory demand.

\section{Materials and methods \\ Study approach}

By combining long-term empirical estimates of parameters and responses (estimated during 1986-1995) with simulation modeling, we quantify direct effects of observed (i.e., natural) variability in walleye population structure, level of consumption, and temperature regime on prey consumption and growth by Lake Erie walleye. Consideration of natural between-basin, among-year variability of these factors is very important in teasing apart their independent effects on walleye populations. For instance, both temperature regime and population structure differ between the western and central basins; through this modeling effort, we can test for their effects independently.

Specifically, we used a bioenergetics-based simulation model to track individual walleye during April through mid-November of a given year. Modeling individual walleye allowed us to represent physiological processes of individual fish and permitted direct extrapolation to the entire population. Simulation experiments were designed to determine the effects of walleye population structure (age and size structure), annual temperature cycle, and age-specific consumption on walleye growth and consumption (Table 1). To examine growth of walleye from basin-specific and migratory populations, simulation experiments had three distinct walleye population treatments: $(i)$ population remaining in the western basin for the entire growing season, (ii) population remaining in the central basin for the entire growing season, and (iii) a population migrating from the western to the central basin in early June and returning in early September. Characterizing walleye populations as either basin specific or migratory is very important, given differences in temperature regime between Lake Erie's western and central 
Table 1. Design and description of parameter values for simulation experiments and lakewide consumption estimates.

\begin{tabular}{|c|c|c|c|c|}
\hline & \multicolumn{4}{|l|}{ Model parameter } \\
\hline & Population structure & Temperature regime & $p$ & Population size \\
\hline Simulation experiment I & $\begin{array}{l}\text { Year-specific } \\
\text { Basin-specific }\end{array}$ & $\begin{array}{l}\text { Constant across years } \\
\text { Constant across basins } \\
\text { (1990 western basin) }\end{array}$ & $\begin{array}{l}\text { Constant across years } \\
\text { Constant across basins } \\
\text { (mean across years } \\
\text { from western basin) }\end{array}$ & Constant $(20000)$ \\
\hline Simulation experiment III & $\begin{array}{l}\text { Year-specific } \\
\text { Basin-specific }\end{array}$ & $\begin{array}{l}\text { Yearmspecific } \\
\text { Basin-Specific }^{a}\end{array}$ & $\begin{array}{l}\text { Year-specific } \\
\text { Basin-specific }\end{array}$ & Constant $(20000)$ \\
\hline
\end{tabular}

Note: Model parameters whose effects are being tested in a given experiment are shown in bold. Actual parameter values are derived from empirical measurements in Lake Erie, 1986-1995 (see Materials and methods).

"Includes migratory population in which walleye move between the western and central basins.

basins. With rapid spring warming rates, no depth stratification (i.e., well-mixed waters), and high summer water temperatures, the western basin of Lake Erie represents a very different growing environment than the central basin, which warms later in the year, stratifies normally, and generally has lower summer water temperatures. Thus, residence within a given basin or seasonal movement between the western and central basins will significantly influence walleye growth and consumption.

\section{Characterizing daily temperature regimes}

Annual basin-specific temperature regimes were generated to simulate the temperature regime that a western basin, central basin, or migratory walleye might experience during the growing season, which we defined as 1 April through 15 November. Daily basin-specific estimates of surface water temperature (depth $<1 \mathrm{~m}$ ) represent means taken from multiple point estimates of temperature from that basin. Temperature data were received from multiple state, federal, and provincial agencies (Sandusky and Fairport fisheries stations, ODNR-ODW; St. Lawrence Basin Project, National Water Research Institute, and Lake Erie Management Unit (Ontario Ministry of Natural Resources); Monroe Water Authority (Monroe, Mich.); National Oceanic and Atmospheric Administration Coast-Watch (Great Lakes Environmental Research Laboratory)). When combined, these data sets provide widespread spatial coverage of surface water temperatures within a basin, allowing us to generate realistic basin-wide temperature estimates for any given day within a year during 1986-1995. If no temperatures were recorded for a given day, we assumed that the temperature from the previous day described that day. To 
simulate the thermal regime experienced by migratory walleye, we constructed a temperature data set that was a composite of western and central basin temperature regimes. To match the apparent timing of this seasonal movement, western basin temperatures were used for 1 April through 31 May, central basin temperatures were used for 1 June through 31 August, and western basin temperatures were used for 1 September through 15 November (M. Turner (ODNR-ODW), R. Haas (Michigan Department of Natural Resources), and S. Nepszy (Ontario Ministry of Natural Resources), unpublished tagging data).

\section{Characterizing simulated walleye populations}

Simulated walleye populations were composed of age-classes 2 through 10+. Reliable population estimates were not available for walleye younger than age 2; thus, they were excluded. Annual walleye age structure (proportion of the population within a given age-class) in Lake Erie was generated by catch-at-age analysis (i.e., CAGEAN; Deriso et al. 1985) conducted by the Walleye Task Group of the Lake Erie Committee, Great Lakes Fishery Commission, modified to include fish age 7 through $10+$. We assumed that age structure was constant among western basin, central basin, and migratory walleye populations. Age- and sex-specific size structure data (length-frequency and weight-frequency distributions) were obtained from annual ODNR-ODW fall gillnet surveys. Walleye from a given age-class and sex were grouped according to $10-\mathrm{g}$ weight increments, and we calculated the proportion of individuals in a given weight-class for each age-class and sex. To generate representative weight distributions for walleye in age-classes 7 through 10 (age-classes traditionally underrepresented in gillnet samples), we pooled all individuals of these ages captured in fall gillnet sampling across all years of interest (1986-1995). From these data, we were able to construct robust weight distributions representative of these older walleye.

Coupling age and size structure information, we generated simulated walleye populations ( $N=20000$ individual walleye, characterized by a 50:50 sex ratio) in which walleye were randomly (using the RAN2 subroutine; Press et al. 1989) assigned to an age-class in proportion to the age composition of the population for a specific year. Next, each simulated walleye was assigned to a 10-g age- and sex-specific weight-class in proportion to the weight-frequency distribution for that age-class and sex. Once assigned to an age/sex/weight-class, the exact weight of each walleye within the 10-g weight-class was randomly chosen (using RAN2; Press et al. 1989) from a uniform distribution.

Based on weight-at-age, female walleye grow faster than male walleye, resulting in sexual dimorphism. To determine if female walleye grew more because of higher consumption rates, we examined sex-specific consumption patterns for Lake Erie walleye and found that females did exhibit greater weight-specific consumption. Alternatively, females may feed more frequently than males; however, our analyses could not assess this possibility.

Factors influencing sexual dimorphism have been investigated for a closely related percid, yellow perch, in which estrogenic compounds stimulate female growth, whereas androgenic compounds retard male growth rates (Malison et al. 1985, 1988). For both sexes, these changes in growth rate were related to maturation. For walleye, we assumed that similar hormonal effects may be driving the apparent sexual dimorphism. Given that the physiological mechanism for sex-specific differences was unknown, we did not change parameters associated with walleye consumption rate. Rather, we adjusted the daily growth increment of female walleye. Thus, we accounted for changes in weight-specific consumption indirectly by increasing growth rate rather than consumption (as we found no evidence for male-female 
differences in consumption rate).

To determine the appropriate adjustment, we used fall weight-at-age data (from walleye captured in ODNR-ODW fall gillnet surveys) to calculate the sex-specific change in mean weight for a given age-class of walleye on an annual time step. We used these data to estimate constant annual growth increments for males (eq. 1) and females (eq. 2):

$$
\begin{aligned}
& \text { (1) } X_{t+1, \varangle}=X_{t, 3}+\Delta_{\delta} \\
& \text { (2) } X_{t+1, q}=X_{t, q}+\Delta_{\diamond}+\omega
\end{aligned}
$$

where $X_{t i}$ is mean wet weight of individuals of sex $i$ in a given walleye age-class in October of year $t, \Delta_{\diamond}$ is the estimated annual growth increment for male walleye (i.e., change in wet weight from year $t$ to year $t+1$ ), and $\Delta_{\hat{\delta}}+\omega$ is the estimated annual growth increment for females. Based on inspection of data associated with multiple walleye age-classes, we assumed that $\omega$ was a constant value over all ages and initial sizes, with a value of $\omega=100 \mathrm{~g} \cdot \mathrm{year}^{-1}$. Given that the simulation model uses a daily time step, eq. 1 was converted to growth on a daily time step:

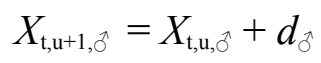

where $X_{\mathrm{t}, \mathrm{u}+1, \widehat{\diamond}}$ is wet weight of a male walleye on simulation day $u$ in year $t$ and $d_{\widehat{\delta}}$ is the constant daily growth increment for male walleye (i.e., change in wet weight from day $u$ to day $u+1$ ), calculated via the bioenergetics component of the simulation model. Thus, on each simulation day, weight-specific consumption (and thus, daily growth increment) was calculated in the same fashion for male and female walleye. To account for the higher level of growth associated with female walleye, we converted $\omega$ to a daily growth adjustment $\alpha$ of 0.4386 g-day $^{-1}(\alpha=\omega / 228$ simulation days) and added $\alpha$ to the bioenergetics-calculated female walleye weight at the end of each simulation day:

$$
X_{\mathrm{t}, \mathrm{u}+1, \uparrow}=X_{\mathrm{t}, \mathrm{u} \uparrow}+\mathrm{d}_{\delta}+\alpha .
$$

\section{Calculating age-specific $p$ values}

Walleye prey consumption was modeled using the $p$ value, a scaling factor used in bioenergetics modeling (Hewett and Johnson 1992). The $p$ values are weight and temperature dependent and represent the proportion of maximum daily feeding rate attained by an individual fish. For example, a walleye that feeds at $100 \%$ of its maximum feeding rate will have a $p$ value of 1.0 , whereas one that feeds at $40 \%$ of its maximum feeding rate will have a $p$ value of 0.4 . We back-calculated annual, age-specific $p$ values (using the bioenergetics model; Hewett and Johnson 1992) for walleye in each basin by combining observed growth of walleye captured in ODNR-ODW fall gillnet surveys with annual temperature regimes. For example, we used the bioenergetics model to estimate the $p$ value required to grow a fish from the mean weight of age2 walleye in October 1991 gill nets to the mean weight of age-3 walleye in October 1992 gill nets, given the 1992 western basin temperature regime. Age-specific $p$ values were kept constant for a given simulation year.

\section{Simulation experiment I: influence of walleye population structure}

The first simulation experiment examined the influence of walleye population structure 
(age and size structure) on patterns of walleye growth and consumption. Walleye population structure may be important in determining consumptive demand due to substantial annual variability in walleye abundance and population bio-mass resulting from among-year variability in year-class strength In this experiment, we compared growth (change in population biomass during the growing season) and consumption (total consumption by the walleye during the growing season) of modeled walleye populations having empirically measured age and size structures characteristic of either the western or central basin population. We simulated walleye population structure for each yea: during 1986-1995 keeping temperature regime and agespecific consumption levels constant among all years (Table 1). We used the 1990 western basin temperature regime and parameterized age specific consumption using western basin $p$ values, averaged across all calculated values for each age-class among years. Because we did not know the population structure of the migratory walleye population, the first simulation experiment was done only for western and central basin population treatments.

\section{Simulation experiment II: influence of temperature regime}

The second simulation experiment focused on the independent influence of annual temperature regimes on patterns of walleye growth and consumption. In this experiment, we compared growth (change in population biomass during the growing season) and consumption (total consumption by walleye during the growing season) of modeled walleye experiencing empirically estimated temperature regimes characteristic of the western basin, central basin, or migratory populations. We simulated temperature regimes for each year during 1986-1995 for all three population treatments, keeping initial population structure and age-specific consumption levels constant among all years (Table 1). We used the age and size structure of the 1990 western basin walleye population to create a single initial population that was used in each run of this simulation experiment. Finally, we parameterized age-specific consumption using western basin $p$ values, averaged across calculated values for each age-class among all years.

\section{Simulation experiment III: combined effects of population structure, age-specific consumption, and temperature regime}

The third simulation experiment focused on the combined effects of walleye population structure, age-specific consumption level, and annual temperature regime on year-specific patterns of walleye growth (change in population biomass during the growing season) and consumption (total consumption by walleye during the growing season). We used initial walleye population structure, consumption level, and annual temperature regime measured empirically for each year and population treatment (Table 1). Because we did not have estimates of population structure for the migratory walleye population, we used the age and size structure of the western basin population to characterize the initial size distribution of migratory walleye populations.

\section{Estimating lakewide prey consumption by walleye}

By coupling age-specific estimates of daily consumption generated by simulation experiment III with annual CAGEAN population estimates (Table 1), we estimated lakewide prey consumption by walleye populations during 1986-1995. For these estimates, we assumed that the age and size structure of simulated populations was representative of the lakewide walleye population. As noted previously, age- 0 and age-1 walleye were not included in these analyses due to inadequate empirical data; if we included these age-classes, predatory demand 
estimates likely would increase somewhat. When describing "lakewide" walleye populations, we are referring specifically to western and central basin walleye stocks. CAGEAN population estimates are calculated based solely on western and central basin data, simply due to the fact that the eastern basin walleye stock appears to be quite small. Given the lack of information regarding the proportion of the lakewide population that can be characterized as western basin, central basin, or migratory walleye, we conducted separate lakewide consumption estimates for

Fig. 1. Simulation results for the effects of walleye population structure on walleye growth and consumption during 1986-1995 in the western and central basins of Lake Erie (simulation experiment I). Individual population treatments are the western basin (hatched bars) and central basin (open bars) populations. (A) Initial population biomass for simulated walleye populations across years. (B) Change in population biomass for simulated walleye populations across years. (C) Total consumption by simulated walleye populations across years.
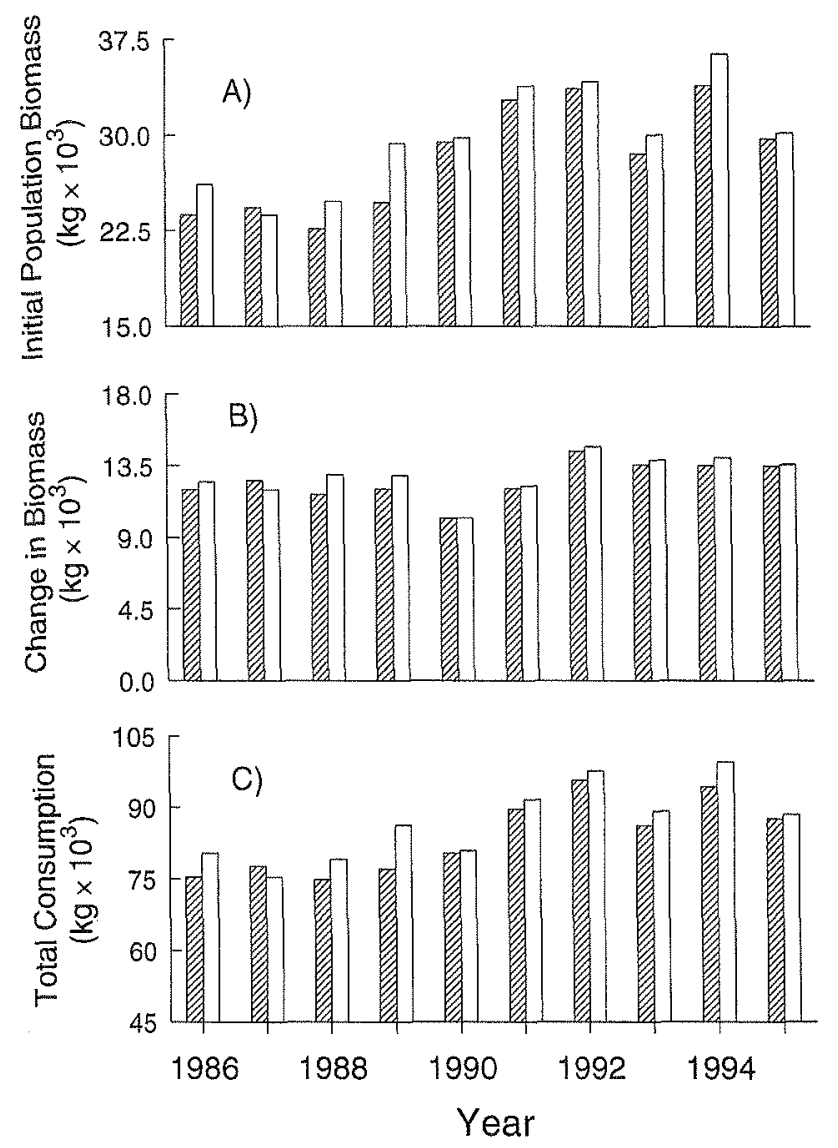

each population treatment. We also conducted a fourth extrapolation assuming that the lakewide walleye population was divided equally among the three population treatments. We generated annual estimates of lakewide consumption (LWC) for each extrapolation:

$$
\mathrm{LWC}=\sum_{i=91}^{319} \sum_{j=2}^{10}\left(\frac{C_{i j}}{n_{j}} \times N_{j}\right)
$$


where $i$ is day of the year (range $=91$ ( 1 April) through 319 (15 November)) and $j$ is age-class (range $=2$ through 10). Daily consumption per lakewide walleye in age-class $j$ was calculated by dividing daily consumption by all simulated walleye in age-class $j\left(C_{i j}\right)$ by the abundance of simulated walleye in age-class $j\left(n_{j}\right)$ and then multiplying this value by the CAGEAN estimate of the lake-wide abundance of age-class; $j\left(N_{j}\right)$. Year-specific estimates of consumption by the lakewide walleye population were generated by summing consumption by all age-classes across all days in a given year.

\section{Results}

\section{Simulation experiment I: influence of walleye population structure}

This experiment focused on the effects of walleye population structure (age and size structure) on among-year variability of basin-specific growth and consumption. Basin-specific initial population biomass was quite variable among years (Fig. 1A). In general, central basin populations had higher initial population biomass (Fig. 1A) and slightly larger increases in biomass (Fig. 1B) and total consumption during the growing season (Fig. 1C) than western basin populations because central basin walleye were generally larger than western basin walleye at the beginning of the growing season.

To account for basin-specific differences in initial biomass and to determine if there was a consistent basin-specific advantage relative to growth rate, we calculated a basin-specific mean for the change in population biomass (final biomass minus initial biomass) for each population treatment across all simulation years. The mean (among-year) change in biomass growth did not differ between the western and central basin populations as a function of walleye population structure alone (Table 2).

\section{Simulation experiment II: influence of temperature regime}

The second simulation experiment focused on the influence of temperature alone on patterns of walleye growth and consumption. In this case, walleye population structure was held constant among all population treatments and across all simulation years. Within a population treatment, final population biomass varied greatly among years, primarily due to variation among years in growth during summer (Fig. 2). Spring and fall growth differed little among years. This among-year variation in walleye biomass accrual during summer was much higher in the western basin than in the central basin or migratory population treatments, leading to higher among-year variability in western basin walleye growth rates (Fig. 2).

Table 2. Mean ( $\pm 1 \mathrm{SE}$ ) change in population biomass (final biomass (kg) minus initial biomass (kg); mean taken across all simulation years) in each simulation experiment for western basin, central basin, and migratory (between western and central basins) walleye populations in Lake Erie.

\begin{tabular}{llll} 
& $\begin{array}{l}\text { Western basin } \\
\text { walleye populations }\end{array}$ & $\begin{array}{l}\text { Central basin } \\
\text { walleye populations }\end{array}$ & $\begin{array}{l}\text { Migratory walleye } \\
\text { populations }\end{array}$ \\
\hline Simulation experiment I & $12558( \pm 386)$ & $12898( \pm 400)$ & Not simulated \\
Simulation experiment II & $9890( \pm 1070)$ & $12610( \pm 582)$ & $13470( \pm 436)$ \\
Simulation experiment III & $12035( \pm 1384)$ & $12981( \pm 1219)$ & $16151( \pm 1970)$ \\
\hline
\end{tabular}


Fig. 2. Population biomass trajectories (1 April through 15 November) resulting from the effects of temperature regime only (across all simulation years; simulation experiment I) for (A) western basin, (B) central basin, and (C) migratory (western and central basins) population treatments in Lake Erie. In cases where individual lines were too close together to distinguish, the lines are grouped and listed in order of decreasing final population biomass.

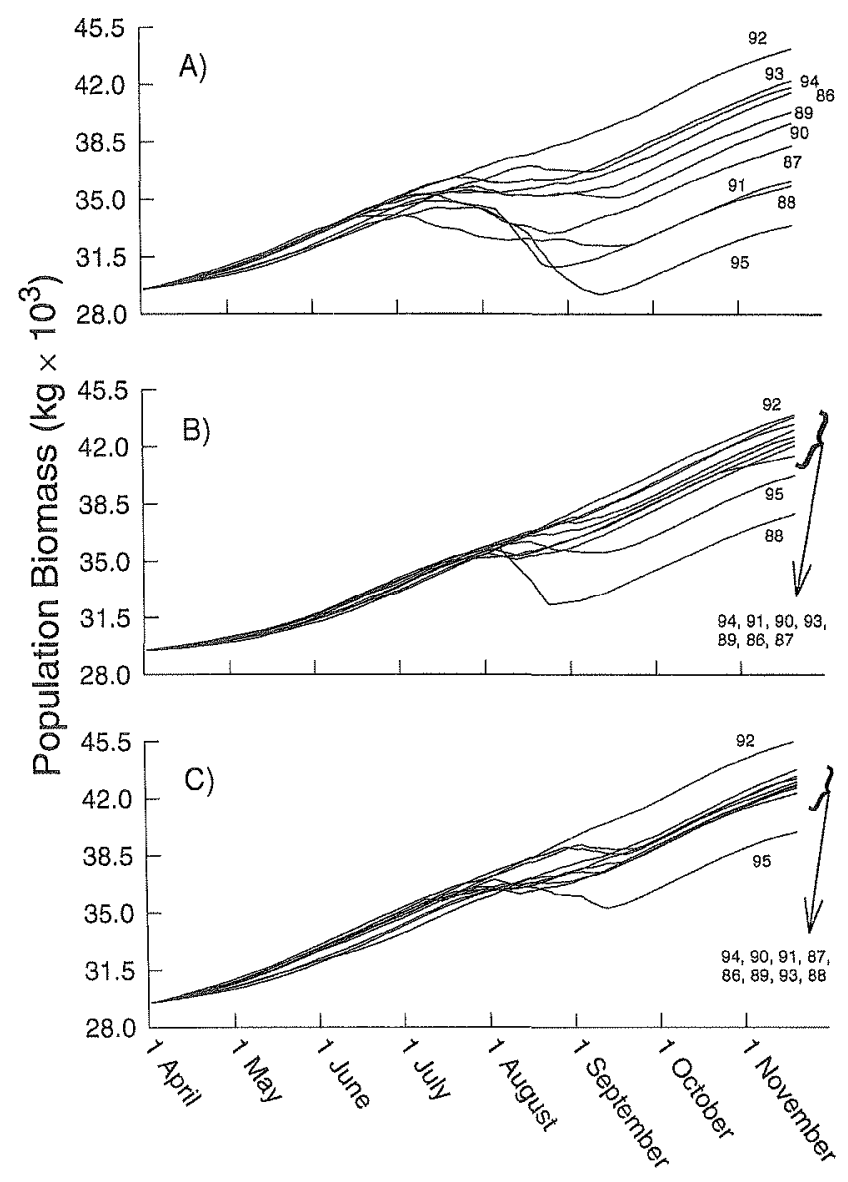

Migratory walleye populations grew most quickly (measured as the change in population biomass during the growing season) in nearly all simulation years, with central basin populations growing only slightly less (Fig. 3A). In contrast, western basin walleye populations had the lowest and most variable levels of growth of all the population treatments across simulation years (Fig. 3A).

In most simulation years, migratory walleye populations consumed the most (summed across the growing season), followed by western basin populations (Fig. 3B). Interestingly, whereas western basin walleye generally consumed more than central basin walleye (Fig. 3B), they also grew less in terms of biomass accrual (Fig. 3A). Lower growth in the western basin may derive from temperatures that generally exceeded optimal temperatures for walleye growth during summer, leading to higher consumption, but reduced growth. 
Fig. 3. Simulation results for the effects of temperature regime on walleye growth and consumption during 19861995 in the western and central basins of Lake Erie (simulation experiment II). Individual population treatments are the western basin (hatched bars), central basin (open bars), and migratory populations (solid bars). (A) Change in population biomass for simulated walleye populations across years. (B) Total consumption by simulated walleye populations across years.
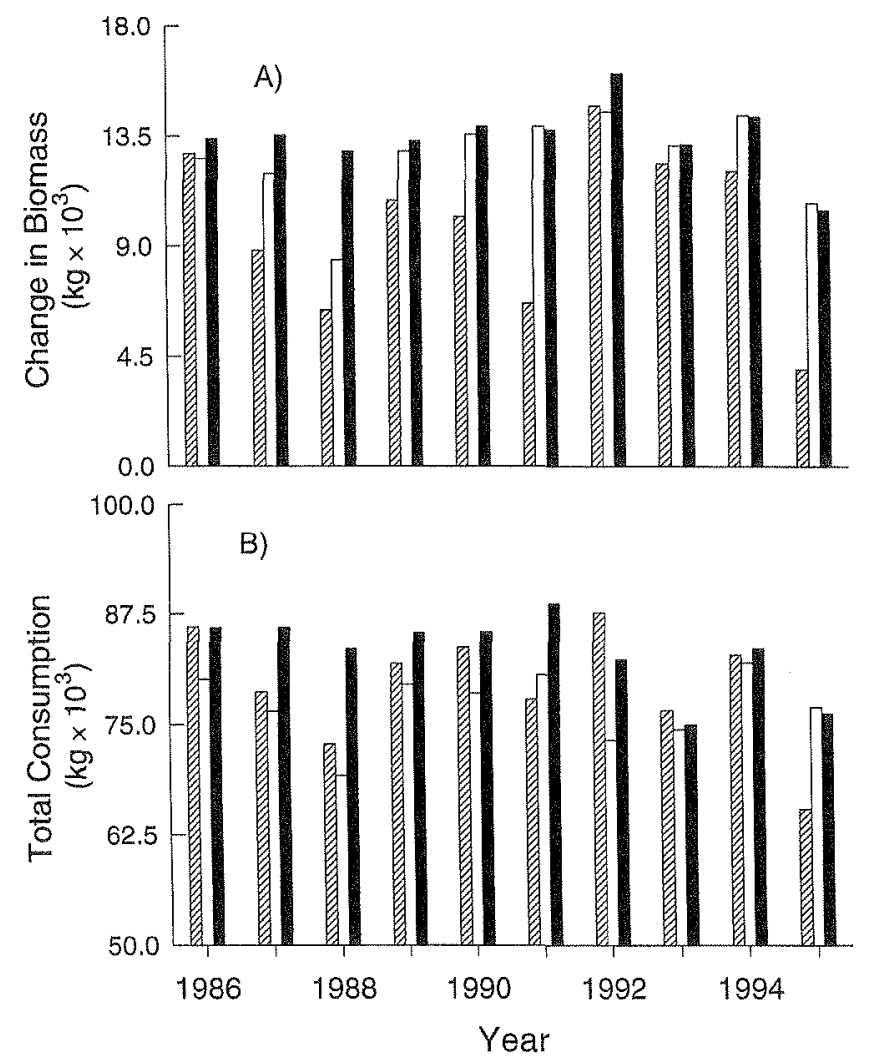

To determine if a treatment-specific growth advantage existed due to temperature regime alone, we calculated a basin-specific mean for the change in biomass (measured as the change in population biomass during the growing season) for each population treatment across all simulation years. In general, both migratory and central basin walleye grew more quickly than western basin walleye (Fig. 3B). High growth in migratory populations may derive from these walleye exploiting growth opportunities in both basins, given that the western and central basins warm at different rates. 
Fig. 4. Temperature regimes of the (A) western and (B) central basins of Lake Erie in 1988 (solid line) and 1992 (broken line) and specific growth rate for a 1000 -g walleye feeding at a constant $p$ value $(0.4)$ as a function of the 1988 (solid line) and 1992 (broken line) temperature regimes in the (C) western and (D) central basins of Lake Erie.

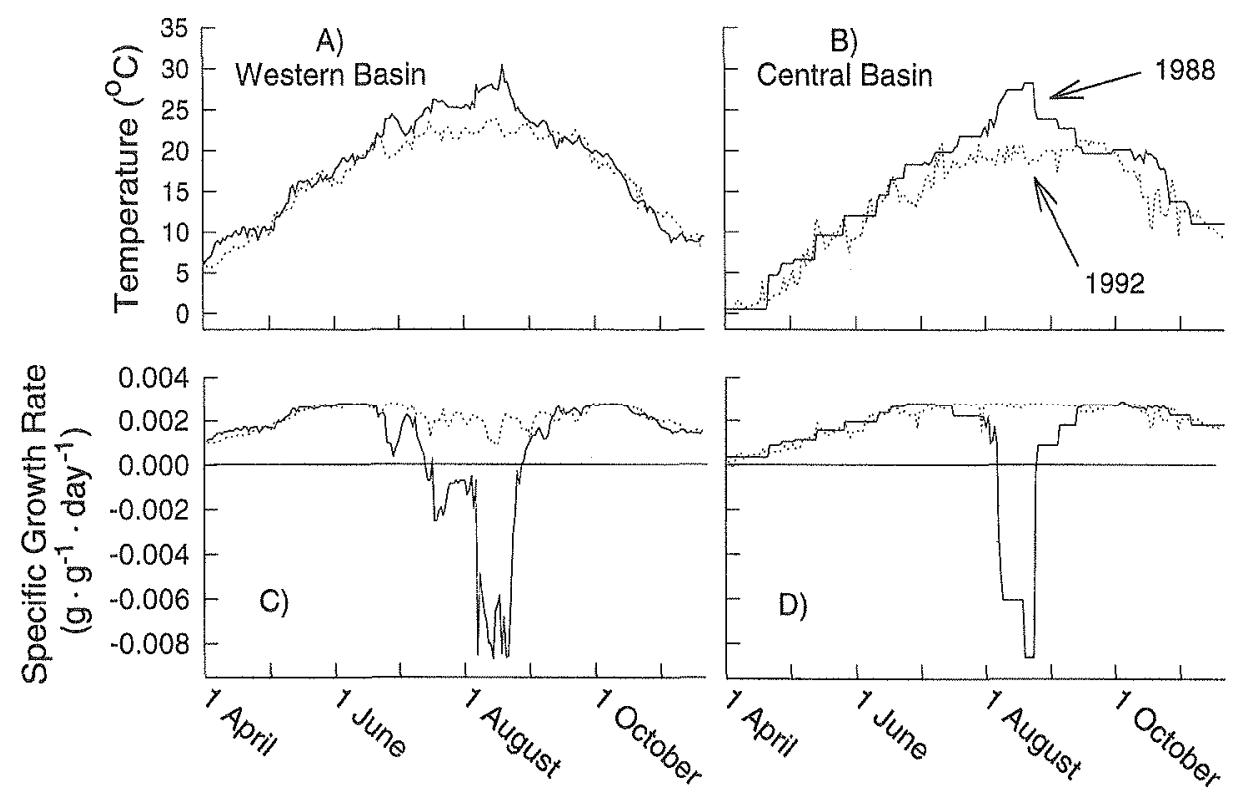

To further illustrate how year-specific temperature regimes influence walleye growth, we examined temporal trends of modeled walleye growth rate (grams per gram per day, calculated using the bioenergetics model for a 1000-g walleye feeding at $p$ value of 0.4) during the 1988 and 1992 growing seasons, years having very different temperature regimes (Fig. 4). In 1988 and 1992, early-season growth was highest in the western basin, owing to faster warming rates than in the central basin. However, by early June, central basin growth surpassed western basin growth, primarily because western basin temperatures exceeded optimal temperatures for walleye growth (Fig. 4). Strong year-to-year variability in temperature regime influenced walleye growth rates. For example, during 1988, modeled growth in both basins became negative during late summer as water temperatures approached $31^{\circ} \mathrm{C}$ (Fig. 4). In contrast, during 1992, a cool year in which water temperatures rarely exceeded $24^{\circ} \mathrm{C}$, walleye growth rates (simulated) were positive through the entire growing season in both basins (Fig. 4).

\section{Simulation experiment III: combined effects of population structure, age-specific consumption, and temperature regime}

The third simulation experiment focused on the combined effects of walleye population structure, age-specific consumption level (as estimated by $p$ values), and annual temperature regime on patterns of walleye growth and consumption. Differences among years in final population biomass could be attributed to differences in initial population biomass and 
differences in growth rates during all seasons (Fig. 5). In contrast with simulation experiment II (effects of temperature regime), among-year differences in final population biomass were not driven solely by differences in summer growth trajectories (Fig. 5).

Initial population biomass for the simulated walleye populations was variable among years and highest in the 1990's (Fig. 6A), primarily due to recruitment of large year-classes from the 1980s into older age-classes. In contrast with simulation experiments I and II, change in population biomass was highly variable (among years) across all three population treatments, with migratory walleye consistently growing more quickly than either the western or central basin populations (Fig. 6B). Interestingly, 1994 had the highest initial population biomass but the lowest levels of consumption and growth across all simulation years (Fig. 6), a pattern not predicted by simulation experiments I and II. Total consumption also varied substantially among population treatments and simulation years; western basin and migratory populations generally had the highest consumption (Fig. 6C).

We calculated a mean change in biomass (measured as the change in population biomass during the growing season) for each population treatment across all simulation years. When yearspecific walleye population structure, variable consumption, and temperature regime were incorporated into the model, migratory walleye populations maintained the high levels of growth conferred by temperature regime alone (Table 2). However, including these factors damped differences in biomass accrual between western and central basin walleye populations (Table 2). Interestingly, among-year variability in all population treatments increased substantially relative to the first two simulation experiments.

\section{Estimating lakewide prey consumption by walleye}

By coupling estimates of consumption from simulation experiment III with CAGEAN population estimates for each simulation year, we estimated lakewide consumptive demand for walleye populations during 1986-1995. Patterns of modeled lakewide consumption consistently tracked trends in walleye abundance (Fig. 7), with a peak in the late 1980's and a decline over the past 7 years. In general, population treatment had little effect on estimates of lakewide consumption. The highest level of lakewide consumption by walleye occurred in 1988, which also had the highest population density of all simulation years (Fig. 7) and also had relatively low levels of growth and consumption (Fig. 6). 
Fig. 5. Population biomass trajectories (1 April through 15 November) resulting from the combined effects of walleye population structure, age-specific consumption rates, and temperature regime (across all simulation years) for (A) western basin, (B) central basin, and (C) migratory (western and central basins) population treatments in Lake Erie (simulation experiment III). In cases where individual lines were too close together to distinguish either initial or final population biomass, the lines are grouped and listed in order of decreasing population biomass.

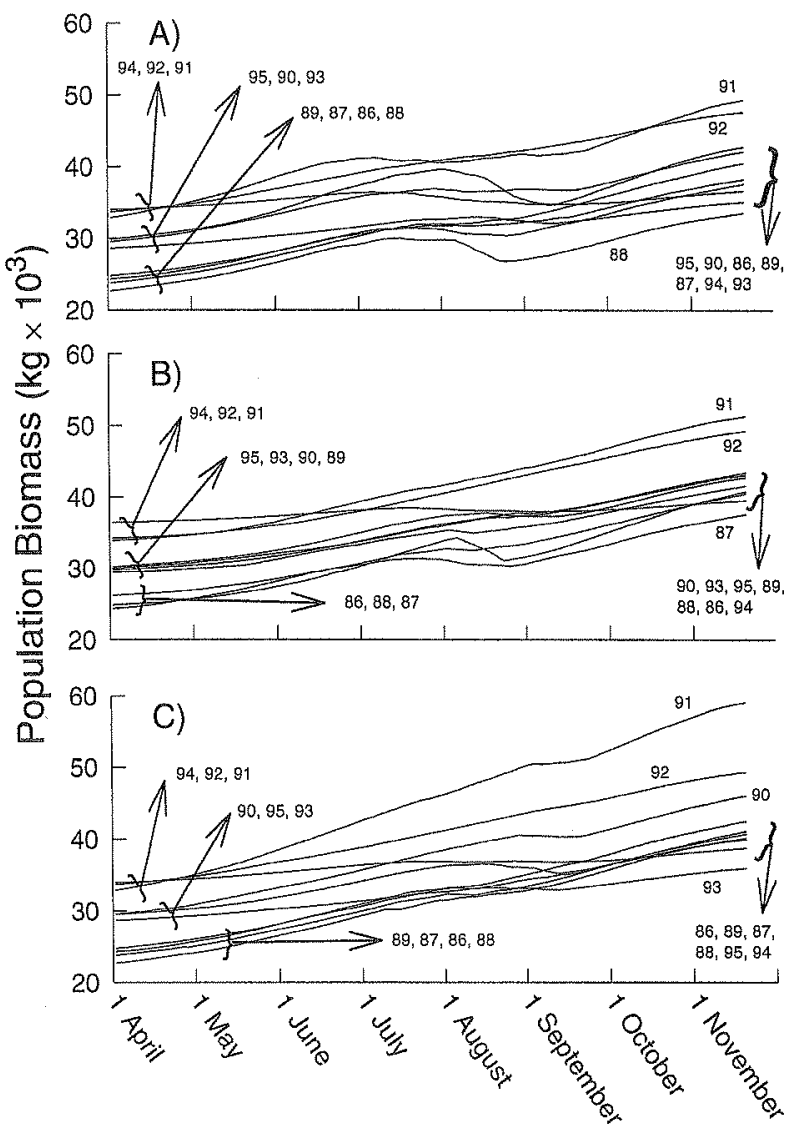

\section{Discussion}

\section{Simulation experiment I: influence of walleye population structure}

Interbasin differences in walleye age and size structure had limited influence on betweenbasin comparisons of annual consumption and growth. Empirical estimates of initial walleye population biomass were variable among years and consistently higher in the central basin than in the western basin. This, coupled with larger individual walleye in the central basin, generally resulted in higher estimates of modeled growth and total consumption for central basin populations relative to western basin populations. As initial population biomass varied among 
Fig. 6. Simulation results for the combined effects of walleye population structure, age-specific consumption rates, and temperature regime on walleye growth and consumption during 1986-1995 in the western and central basins of Lake Erie (simulation experiment III). Individual population treatments are the western basin (hatched bars), central basin (open bars), and migratory populations (solid bars). (A) Initial population biomass for simulated walleye populations across years. (B) Change in population biomass for simulated walleye populations across years. (C) Total consumption by simulated walleye populations across years.

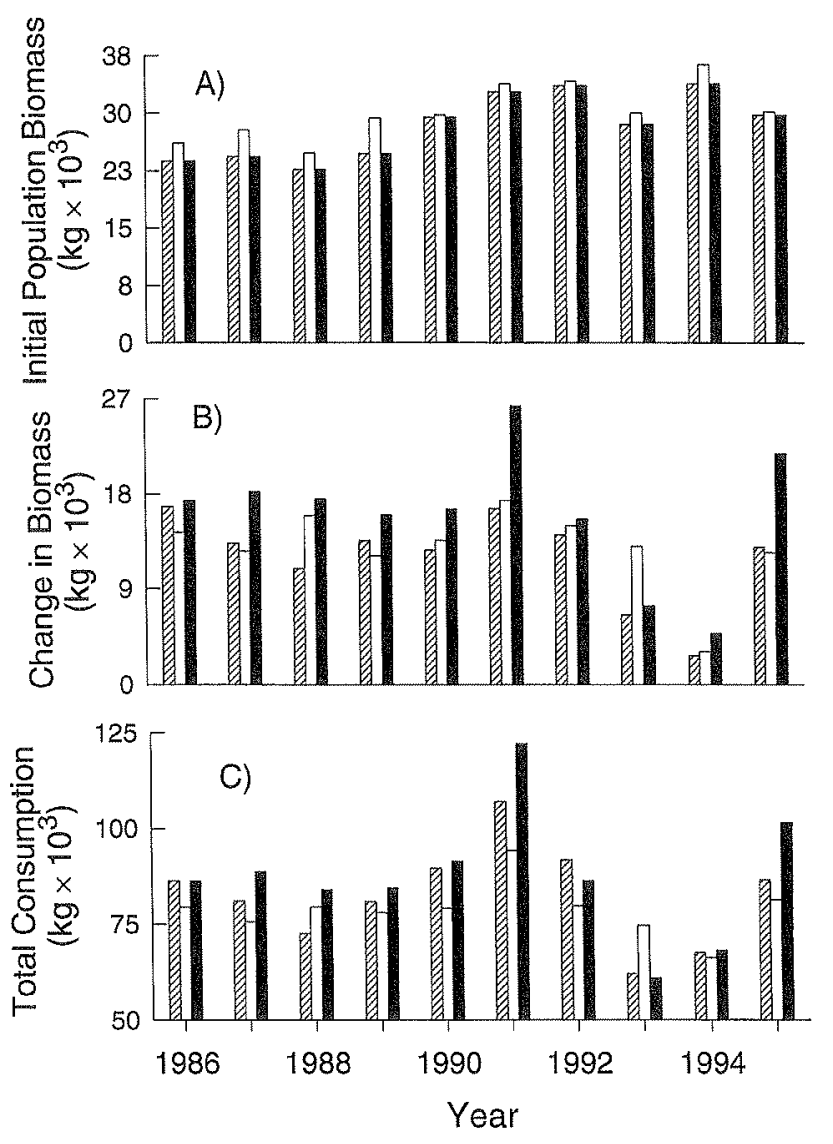

years, so did model estimates of total consumption. However, modeled growth rate (i.e., change in population biomass) did not exhibit high annual variability, nor did it differ greatly between basins. As large year-classes associated with the early to mid-1980's recruited to the lakewide population (resulting in increased initial population biomass), total modeled consumption also increased, demonstrating the importance of incorporating year-specific population structure when estimating the future consumptive demand of Lake Erie walleye.

\section{Simulation experiment II: influence of temperature regime}

Annual temperature regime strongly influenced patterns of consumption and growth by Lake Erie walleye. Western basin populations exhibited strong among-year variability in modeled consumption and growth, which was strongly related to among-year differences in 
summer temperature regime and its direct effects on walleye growth rate. Central basin walleye

Fig. 7. Lake Erie (A) adult walleye (ages 2 through 10+) population size (estimated by CAGEAN) and (B) lakewide estimates of consumption by walleye extrapolated from simulation results during 1986-1995.

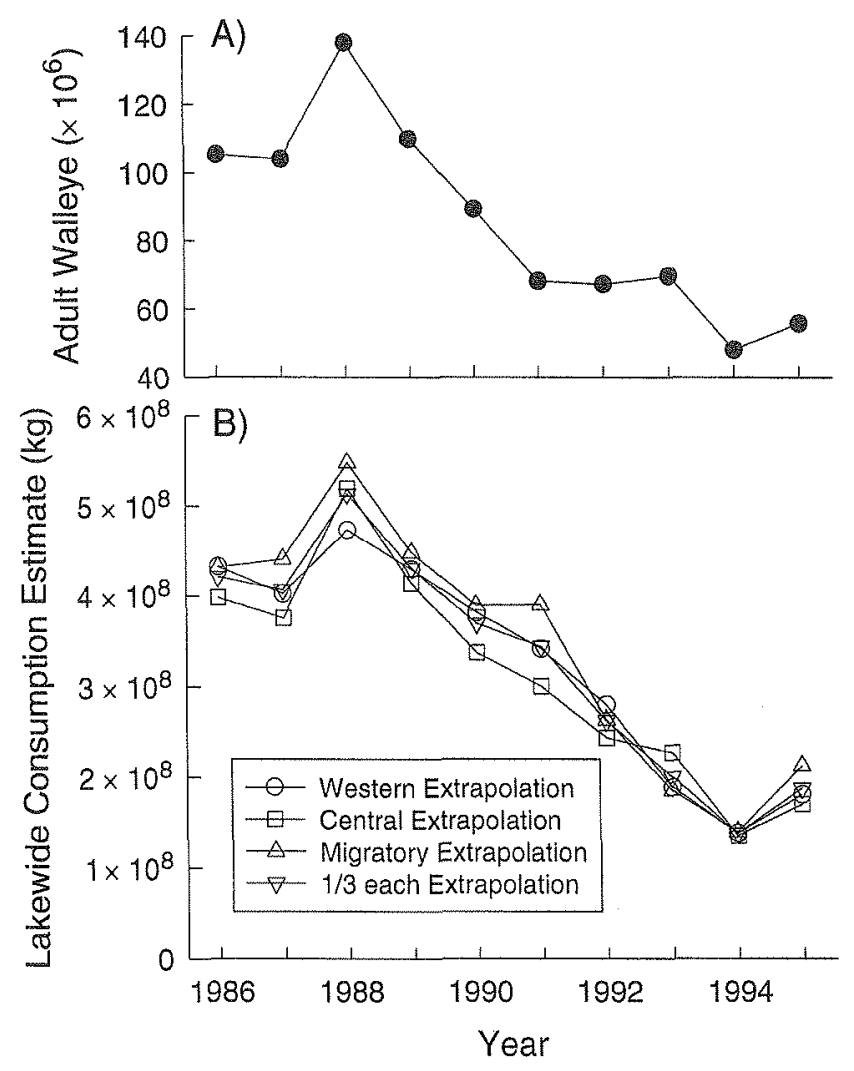

exhibited similar patterns of variability in modeled consumption and growth, but to a lesser extent. In contrast, annual estimates of modeled consumption and growth rate for migratory walleye populations were remarkably stable. This stability derived from how the timing of interbasin walleye movement interacted with interbasin shifts of optimal growth temperatures $\left(<24^{\circ} \mathrm{C}\right)$ for walleye. The western basin warms earlier than the central basin, and thus supports higher walleye growth rates early in the growing season. However, as water temperatures rise in early summer, growth peaks shift from the western to central basin, driving higher walleye growth in the central basin. Walleye that do not move between basins only experience a single growth peak, whereas migratory walleye exploit growth peaks in both basins. Interestingly, migratory timing, as quantified by tagging studies, occurs during early June (M. Turner (ODNRODW), R. Haas (Michigan Department of Natural Resources), and S. Nepszy (Ontario Ministry of Natural Resources), unpublished data), coincident with the basin-to-basin shift in growth peaks. Thus, with the timing of interbasin movement corroborated by tagging data, our modeling effort provides a strong explanation for seasonal walleye movements; simply put, migratory 
walleye will have higher growth rates. In fact, migratory walleye grew faster than central basin walleye (averaged among years), which grew faster than western basin walleye. In general, these simulation results indicate that year-specific, population-specific temperature regimes must be used when quantifying annual trends in walleye growth and consumption.

Summer temperature regime had a strong effect on modeled walleye growth rates in the western basin. In fact, summer water temperatures can be quite high for extended periods and may inhibit walleye growth. When water temperatures exceed $24^{\circ} \mathrm{C}$, walleye growth rates decline (Momot et al. 1977). This decline is exacerbated by lack of access to a thermocline or hypolimnion (given that the western basin does not stratify). In contrast, summer water temperatures experienced by central basin and migratory walleye are generally lower, and although water temperatures can exceed $24^{\circ} \mathrm{C}$, the duration and likelihood of these events are much lower than in the western basin. Thus, summer temperature regime is much less likely to limit central basin and migratory walleye growth than growth of western basin walleye.

\section{Simulation experiment III: combined effects of population structure, age-specific consumption, and temperature regime}

When we combined empirical, year-specific, population-specific estimates of walleye population structure, age-specific consumption rate, and temperature regime, we found different effects on modeled consumption and growth than when we examined effects of population structure and temperature in single-factor experiments (simulation experiments I and II). As in single-factor simulation experiments, all population treatments exhibited strong among-year variability in modeled consumption and growth, with migratory walleye having the highest values. Western and central basin walleye had similar levels of modeled growth; however, western basin walleye typically consumed more prey than central basin walleye. Walleye consumption and growth estimated in simulation experiment III were much lower in 1993 and 1994 than in other years. In contrast, simulation experiments I and II, examining effects of walleye population structure and temperature regime independently, did not predict reductions in consumption and growth for 1993 and 1994; thus, reduced levels of prey consumption likely slowed walleye growth rates during 1993 and 1994. Interestingly, the negative effects of summer temperature regime on western basin walleye growth were greatly reduced by the addition of year-and basin-specific population structure and age-specific consumption rates, indicating that the strong influence of summer temperatures can be damped or compensated for by these factors. Poor agreement between results of single-factor and multiple-factor simulation experiments illustrates the importance of combining information about population structure (an indicator of initial population conditions), consumption rates (a measure of prey availability), and temperature (an indicator of abiotic conditions) in estimating total consumption and growth.

The combined effects of population structure, age-specific consumption, and temperature regime resulted in substantially increased modeled growth rates (averaged among years) for migratory walleye relative to simulation experiments I and II. In contrast, modeled growth rates of nonmigratory walleye from central and, to a lesser extent, western basin populations were not much higher than observed in simulation experiments I and II but were much lower than observed in the migratory population treatment. Among-year variability associated with annual change in walleye population biomass (for all population treatments) increased relative to singlefactor experiments (simulation experiments I and II). Overall, these results suggest that we must combine empirical estimates of walleye population structure, temperature regime, and daily consumption with modeling to predict among-year differences in walleye consumption and 
growth.

As described in the Materials and methods section (under Characterizing simulated walleye populations), female walleye have higher growth rates than male walleye, possibly due to hormonal differences (Malison et al. 1985, 1988). We accounted for this in our simulation modeling through a female-specific daily growth adjustment and believe that this better estimates predatory demand associated with female walleye, which allows greater confidence in our estimates of population-wide predatory demand.

By combining long-term (10 years) empirical estimates of parameters and variables with simulation modeling, we parameterized simulations using actual estimates of natural variability in biotic and abiotic factors. Typically, modelers are limited to parameterizing a process using a calculated distribution (e.g., normal distribution) for variability estimates, whereas we actually tracked the effects of natural variability on model output (walleye consumption and growth) for a given basin-year combination. Empirical estimates of water temperature, walleye age and size structure, and walleye population size were derived from regular, long-term, standardized monitoring programs conducted by state and federal agencies on Lake Erie. Without these monitoring data as model inputs and parameters, we would have been unable to account for natural variability of biotic and abiotic factors in our simulations.

\section{Predatory demand by Lake Erie walleye}

To provide insight into among-year variability of walleye predatory demand, we used annual estimates of walleye population size to extrapolate from our simulated consumption data to consumption by the entire population. Estimated total consumption by western and central basin Lake Erie walleye populations was highest in 1988. However, simulation experiment III suggests that the walleye population of 1991 had a much larger consumptive demand per walleye than did the walleye population of 1988. This difference between simulation results (based on 20 000 walleye) and lakewide consumption estimates (1988, based on 138 million walleye; 1991, based on 68 million walleye) illustrates the importance of accounting for the interaction of lakewide walleye population size with population structure, age-specific consumption rates, and temperature regime when estimating predatory demand. In other words, while population structure, consumption rates, and temperature regime certainly set the potential for years of high consumptive demand, we must consider the cumulative predatory impact of the lakewide population. Thus, even when predatory demand per individual walleye is low, the existence of a large walleye population can drive predatory demand to exceed the capacity of prey supply to support high levels of walleye growth and reproductive potential.

When considering the relationship between predatory demand and prey production in systems with stocked or introduced top predators, the traditional focus has been on the possibility that predatory demand will exceed prey availability, leading to the collapse of prey populations and, ultimately, predator populations (Stewart et al. 1981; Stewart and Ibarra 1991; Jones et al. 1993; Kitchell et al. 1997). However, in systems where predator populations are naturally reproducing, rather than stocked, production of new predator year-classes is likely a function of energy available from prey populations. Thus, there is a natural feedback mechanism in place to buffer predator population growth in the face of low prey availability, allowing prey stocks to recover.

In Lake Erie, strong feedbacks exist between naturally reproducing walleye and their prey; recent evidence suggests that walleye populations rapidly reduce their reproductive output in response to reduced prey availability. Underlying this response is the strong association 
between fall growth and energetic condition of Lake Erie's walleye spawning stock and subsequent age-0 year-class strength (Henderson and Nepszy 1994). The importance of fall growth to reproductive potential is not surprising, as gonadal development (i.e., vitellogenesis, spermatogenesis) is nearly complete by late fall - early winter (Malison et al. 1994; Malison and Held 1996). Whether female walleye spawn in spring is apparently determined by the level of surplus energy for allocation to vitellogenesis during the previous autumn (Henderson and Nepszy 1994). Surplus energy, and consequently, age-0 year-class strength, appears to be strongly related to the fall availability of lipid-rich gizzard shad, preferred walleye prey (Madenjian et al. 1996). In fact, during 1979-1993, fall gizzard shad abundance alone explained $42 \%$ of the variation in walleye age- 0 year-class strength the following spring, contributing substantially to a model (also including parental stock size and spring warming rate) that explained $92 \%$ of the variability in walleye recruitment (Madenjian et al. 1996).

Given that prey fish production in Lake Erie exhibits high among-year variability (Knight and Vondracek 1993), this feedback mechanism has significant implications. Reductions in the availability and quality (e.g., energy density, lipid content) of the prey base likely reduce age-0 walleye production and success in the subsequent year, reducing the potential for substantial short-term (age 0) and long-term (lifetime) additions to population-wide predatory demand. Thus, the rapid (no time lag) reproductive response by walleye to reduced prey availability can defuse potentially explosive predator population growth (where overgrazing of the prey resource is possible) by allowing recovery of prey populations via a reduction in predation pressure on juveniles and adults of many prey species.

Although this feedback mechanism allows rapid reproductive response to low prey availability, it has limited influence on the predatory demand of the extant adult walleye population. Thus, to understand predatory demand, we must consider the predatory inertia of a population (Stewart et al. 1981; Carpenter et al. 1985). Given that walleye are long lived, the predatory demand associated with large cohorts will be exerted on Lake Erie for the entire life span of that year-class (exceeding 12 years, up to 18 years), regardless of prey availability. Therefore, the temporal scale associated with the predatory capabilities of a large walleye yearclass differs from the shorter life spans and reproductive response of the prey assemblage. Thus, when prey availability is low, the extant walleye population may still exceed the capacity of prey production to support it despite the rapidity of the feedback associated with reduced walleye reproductive potential,

While this study is the most current estimate of predatory demand in Lake Erie, our work only represents the consumptive demand of a single species, walleye. If we estimated cumulative predatory demand by all Lake Erie piscivores (e.g., walleye, smallmouth bass (Micropterus dolomieu), burbot (Lota lota), lake trout (Salvelinus namaycush), white bass), the probability of predatory demand exceeding prey availability (or its capacity to support high growth and successful reproduction by these species) would likely increase, particularly when prey abundance is low. While rarely measured, community-level predatory demand (i.e., summed across all piscivores) may prove to be a significant structuring force in aquatic ecosystems. For example, in northern Wisconsin lakes, the combination of offshore walleye populations and inshore northern pike (Esox lucius) populations drove prey to low densities (Kempinger and Carline 1977), lower than with a single predator. Essentially, prey had no habitat refuge from predation; both inshore and offshore represented significant mortality risks. In this case, predator biomass was not as important as the type of predators added (Kempinger and Carline 1977). In other words, as the number of predator species increases, the availability of spatial and temporal 
refuges for prey declines, increasing the probability of prey fish mortality. Overall, increased predator biomass combined with reductions in the availability of prey refuge may lead to predators exceeding system carrying capacity.

\section{Concluding comments}

With recent shifts in the dynamics of lake productivity (Knight 1997), both biotic and abiotic characteristics of Lake Erie have changed substantially (Makarewicz and Bertram 1991). Coupling changes in the Lake Erie ecosystem with recent advances in our understanding of predator-prey interactions, management of walleye and their associated prey has become a significant challenge. For example, while the natural feedback mechanism between predatory demand and prey availability has a rapid effect on walleye reproductive potential, it has limited immediate effects on extant walleye predatory inertia. The complicated nature of these interactions truly creates a dilemma for our understanding and management of the relationship between predatory demand and prey availability. Similarly, given the implications of community-level predatory demand for prey availability, an understanding of the predatory capabilities of other Lake Erie predators, particularly increasing smallmouth bass and burbot populations, seems critical. Given the dependence of Lake Erie predators (particularly walleye) on the prey assemblage, we should focus future research on the influence of biotic and abiotic variability on prey fish recruitment and attempt to identify time lags associated with predator-prey responses to prey fish production. Continued monitoring of the fish community with standardized assessment programs is critical for future insight into predatory demand in Lake Erie. Only by incorporating these data into the decision making process can we truly assess the balance between predatory demand and prey availability (Ney 1990). In recognition of Lake Erie's changing trophic conditions, the Lake Erie Committee of the Great Lakes Fishery Commission drafted fish community objectives that support management of food web structure and maintenance of a diverse forage base to sustain production by predators, particularly walleye (Lake Erie Committee 1997). To achieve long-term stability and sustainability of Lake Erie's walleye population and prey fish assemblage, fishery managers may need to regulate predatory demand among all piscivores, as opposed to walleye alone.

\section{Acknowledgements}

We thank Paula T. Edersheim for technical assistance during this project. Helpful reviews of drafts of this manuscript were provided by Chuck Madenjian, Joe Margraf, John Roff, and an anonymous reviewer. Support for this project was provided by a University Fellowship from the Graduate School of the Ohio State University (to M.W.K.) and by Federal Aid in Sportfish Restoration F-69-P, administered jointly by the U.S. Fish and Wildlife Service and the Ohio Division of Wildlife, and by the Department of Zoology, Ohio State University.

\section{References}

Carpenter, S.R., Kitchell, J.F., and Hodgson, J.R. 1985. Cascading trophic interactions and lake productivity. BioScience, 35: 634-639.

Deriso, R.B., Quinn, T.J., II, and Neal, P.R. 1985. Catch-age analysis with auxiliary information. Can. J. Fish. Aquat. Sci. 42: 815-824.

Francis, J.T. 1992. Prey selectivity by walleye in Lake Erie: an historical and inter-basin comparison. Master's thesis, Ohio State University, Columbus, Ohio.

Hartman, K.J., and Margraf, F.J. 1992. Effects of prey and predator abundances on prey consumption and growth of walleyes in Lake Erie. Trans. Am. Fish. Soc. 121: 245-260.

Hatch, R.W., Nepszy, S.J., Muth, K.M., and Baker, C.T. 1987. Dynamics of the recovery of the western Lake Erie walleye (Stizostedion vitreum vitreum) stock. Can. J. Fish. Aquat. Sci. 44(Suppl. 2): 15-22. 
Henderson, B.A., and Nepszy, S.J. 1994. Reproductive tactics of walleye (Stizostedion vitreum) in Lake Erie. Can. J. Fish. Aquat. Sci. 51: 986-997.

Hewett, S.W., and Johnson, B.L. 1992. Fish bioenergetics: model 2. Univ. Wis. Sea Grant Tech. Rep. WIS-SG-92250. University of Wisconsin, Madison, Wis.

Jones, M.J., Koonce, J.F., and O'Gorman, R. 1993. Sustainability of hatchery-dependent salmonine fisheries in Lake Ontario: the conflict between predator demand and prey supply. Trans. Am. Fish. Soc. 122: 1002-1018.

Kempinger, J.J., and Carline, R.F. 1977. Dynamics of the walleye (Stizostedion vitreum vitreum) population in Escanaba Lake, Wisconsin, 1955-72. J. Fish. Res. Board Can. 34: 1800-1811.

Kitchell, J.F., Schindler, D.E., Ogutu-Ohwayo, R., and Reinthal, P.N. 1997. The nile perch in Lake Victoria: interactions between predation and fisheries. Ecol. Appl. 7: 653-664.

Kitchell, J.R, Stewart, D.J., and Weininger, D. 1977. Application of a bioenergetics model to yellow perch (Perca flavescens) and walleye (Stizostedion vitreum vitreum). J. Fish. Res. Board Can. 34: 1922-1935.

Knight, R.L. 1997. Successful interagency rehabilitation of Lake Erie walleye. Fisheries (Bethesda), 22(7): 16-17.

Knight, R.L., and Vondracek, B. 1993. Changes in prey fish populations in western Lake Erie, 1969-88, as related to walleye, Stizostedion vitreum, predation. Can. J. Fish. Aquat. Sci. 50: 1289-1298.

Knight, R.L., Margraf, F.J., and Carline, R.F. 1984, Piscivory by walleyes and yellow perch in western Lake Erie. Trans. Am. Fish. Soc. 113; 677-693.

Lake Erie Committee. 1997. Lake Erie fish community goals and objectives. Version 8. Lake Erie Committee, Great Lakes Fishery Commission, Ann Arbor, Mich.

Madenjian, C.R, Tyson, J.T., Knight, R.L., Kershner, M.W., and Hansen, M.J. 1996. First-year growth, recruitment, and maturity of walleyes in western Lake Erie. Trans. Am. Fish. Soc. 125: 821-830.

Makarewicz, J.C., and Bertram, R 1991. Evidence for the restoration of the Lake Erie ecosystem. BioScience, 41: 216-223.

Malison, J.A., and Held, J.A. 1996. Reproduction and spawning in walleye (Stizostedion vitreum). J. Appl. Ichthyol. 12: $153-156$.

Malison, J.A., Best, CD., Kayes, T.B., Amundson, C.H., and Went-worth, B.C. 1985. Hormonal growth promotion and evidence for a size-related difference in response to estradiol-17ß in yellow perch (Perca flavescens). Can. J. Fish. Aquat. Sci. 42: 1627-1633.

Malison, J.A., Kayes, T.B., Wentworth, B.C., and Amundson, C.H. 1988. Growth and feeding responses of male versus female yellow perch (Perca flavescens) treated with estradiol-17ß. Can. J. Fish. Aquat. Sci. 45: 1942-1948.

Malison, J.A., Procarione, L.S., Barry, T.R, Kapuscinski, A.R., and Kayes, T.B. 1994. Endocrine and gonadal changes during the annual reproductive cycle of the freshwater teleost, Stizostedion vitreum. Fish Physiol. Biochem. 13: 473-484.

Mills, E.L., Leach, J.H., Carlton, J.T., and Secor, C.L. 1993. Exotic species in the Great Lakes: a history of biotic crises and anthropogenic introductions. J. Gt. Lakes Res. 19: 1-54.

Momot, W.T., Erickson, J., and Stevenson, F. 1977. Maintenance of a walleye, Stizostedion vitreum vitreum, fishery in a eutrophic reservoir. J. Fish. Res. Board Can. 34: 1725-1733.

Ney, J.J. 1990. Trophic economics in fisheries: assessment of demand-supply relationships between predators and prey. Rev. Aquat. Sci. 2: 55-81.

Press, W.H., Flannery, B.P., Teukolsky, S.A., and Vetterling, W.T. 1989. Numerical recipes: the art of scientific computing (FORTRAN version). Cambridge University Press, New York.

Stewart, D.J., and Ibarra, M. 1991. Predation and production by salmonine fishes in Lake Michigan, 1978-88. Can. J. Fish. Aquat. Sci. 48: 909-922.

Stewart, D.J., Kitchell, J.F., and Crowder, L.B. 1981. Forage fishes and their salmonid predators in Lake Michigan, Trans. Am. Fish. Soc. 110: 751-763. 